\title{
Performance of creatinine and cystatin C-based glomerular filtration rate estimating equations in a European HIV-positive cohort
}

\author{
Amandine Gagneux-Brunon ${ }^{\mathrm{a}, \mathrm{b}, \mathrm{c}}$, Pierre Delanaye ${ }^{\mathrm{d}}$, Nicolas Maillard $^{\mathrm{b}, \mathrm{c}}$, Anne Fresard $^{\mathrm{a}, \mathrm{c}}$, Thierry Basset ${ }^{\mathrm{e}}$, Eric \\ Alamartine $^{\mathrm{b}, \mathrm{c}}$, Frédéric Lucht ${ }^{\mathrm{a}, \mathrm{c}}$, Hans Pottel $^{\mathrm{f}}$ and Christophe Mariat ${ }^{\mathrm{b}, \mathrm{c}}$ \\ ${ }^{a}$ Department of Infectious and Tropical Diseases, CHU Hôpital Nord, Saint-Etienne, France \\ ${ }^{b}$ Department of Nephrology, Dialysis, Transplantation and Hypertension, CHU Hôpital Nord, Saint-Etienne, France \\ ${ }^{c}$ Groupe Immunité des Muqueuses et Agents Pathogènes, EA 3064, University Jean Monnet, Saint-Etienne, PRES Université de Lyon, France \\ ${ }^{d}$ Department of Nephrology-Dialysis-Hypertension, University of Liège, CHU Sart Tilman, Liège, Belgium \\ ${ }^{e}$ Laboratory of Toxicology and Pharmacology, CHU Hôpital Nord, Saint-Etienne, France \\ ${ }^{f}$ Interdisciplinary Research Center, University of Leuven, Kulak, Kortrijk, Belgium.
}

\begin{abstract}
Objective: To validate glomerular filtration rate (GFR) estimating equations in Caucasian HIV-infected patients based on serum creatinine and/or serum cystatin $\mathrm{C}$.

Design: Single-center, cross-sectional evaluation of the predictive performance of GFR estimators

Methods: GFR was measured by iohexol plasma clearance. Serum creatinine (Scr) and serum cystatin C (Scyst) were measured by traceable and standardized methods. We evaluated the performance of the Modification of Diet in Renal Disease (MDRD) and the CKD-Epidemiology Collaboration (CKD-EPI) equations. We also studied the performance of the cystatin C-based equation (CKD-EPI Scyst) and the combined cystatin and creatinine-based equation (CKD-EPI combined), as recently proposed by the CKD-EPI group.

Results: Two hundred and three subjects (18\% of women) were included. Mean age was $49 \pm 10$ years. Mean measured GFR (mGFR) was $95 \pm 24 \mathrm{~mL} / \mathrm{min} / 1.73 \mathrm{~m}^{2}$. CKD-EPI and CKD-EPI combined significantly outperformed the MDRD equation. The percentage of estimating results within $30 \%$ of mGFR was $75 \%, 82 \%$ and $81 \%$ for the MDRD, CKD-EPI and CKD-EPI combined equation, respectively. Results favoring the CKDEPI and CKD-EPI combined equation were especial ly observed for patients with $\mathrm{mGFR}$ over $90 \mathrm{~mL} / \mathrm{min} / 1.73$ $\mathrm{m}^{2}$.

Conclusion: In our European HIV cohort, we confirmed that the creatinine-based CKD-EPI equation should replace MDRD study equation. However, global performance of this equation remains worse than the performance observed in the general population. This lesser performance is particularly relevant in patients with measured GFR under and around $60 \mathrm{~mL} / \mathrm{min} / 1.73 \mathrm{~m}^{2}$. Moreover, the specific interest of Scyst-based equations is not confirmed in this population.
\end{abstract}

Keywords : chronic kidney disease ; creatinine ; cystatin C ; glomerular filtration rate ; HIV

\section{Introduction}

An accurate tool for estimating glomerular filtration rate (GFR) in HIV-infected patients is both necessary and challenging. It is necessary because some of the most active anti-retroviral drugs are either nephrotoxic and/or undergo a renal metabolism that requires dosage adjustment in case of decreasing GFR [1]. Likewise, a reliable evaluation of GFR is critical for the detection of Chronic Kidney Disease (CKD) and its related complications which are becoming particularly prevalent in those patients [2,3]. In the meantime, estimating renal function remains challenging mainly due to the fact that serum creatinine (Scr), as a GFR marker, is likely to be suboptimal in those patients prone to alteration and variation of their muscle mass [4].

Current guidelines of the Infectious Disease Society of America recommend the use of the Modification of Diet in Renal Disease (MDRD) study equation for estimating GFR in HIV-infected patients [5]. This equation is however known to underestimate the true level of renal function in patients with normal, or close to normal GFR values [6,7]. The use of this equation is thus problematic for the detection of CKD and often leads to overdiagnosis $[8,9]$. The CKD-Epidemiology Collaboration (CKD-EPI) equation has been specifically 
developed to correct the GFR underestimation induced by the MDRD study equation [10]. Several, but not all, studies have demonstrated that this equation offers better performance than the MDRD study equation [11-13].

Another step toward the amelioration of GFR evaluation is to turn to a more reliable marker of GFR than Scr. Serum cystatin C (Scyst) has the potential to circumvent many of the shortcomings of Scr and has long been proposed as a promising GFR biomarker [14]. Additionally, new drugs interfering with tubular secretion of Scr (e.g. dolutegravir and cobicistat) are becoming available $[15,16]$. In this context, GFR estimation based on Scyst might be clinically useful. Thus far, a thorough evaluation of Scyst has however been hampered by the absence of standardization for Scyst measurement. Very recently, a certified reference material has been characterized and developed for Scyst [17], making traceability and standardization of Scyst measurement possible. Two equations specifically developed in order to be used with standardized Scyst, have been validated in a large population: the Scyst-based CKD-EPI equation (CKD-EPI Scyst) - incorporating Scyst alone - and the Scyst/ Scr-based CKD-EPI equation (CKD-EPI combined) [18].

In HIV infected patients, a few studies - with contradictory results - have sought to evaluate whether alternative Scyst and/or Scr-based equations might improve GFR estimation in comparison to the MDRD study Equation [19-24]. All these studies had however limitations [4]. Very recently, Inker and colleagues reported that the CKD-EPI equation along with the two new equations based on Scyst were all significantly more accurate than the MDRD study equation in a cohort of 200 HIV positive patients [25]. Importantly, while it is so far the only study that has used calibrated Scr and Scyst, the Inker study has exclusively enrolled North American patients. Given the well-known differences in ethnicity, body composition, conditions of HIV acquisition and prevalence of viral co-infection, their findings do not necessarily extend to non-US populations.

Using standardized measures and similar methodology we thus studied the performance of these new CKD-EPI equations with the aim to recommend the most appropriate equation for practioners taking care of HIV-infected patients in Europe.

\section{Subjects and Methods}

\section{Study Population}

Patients were recruited from the department of infectious diseases of the university hospital of Saint-Etienne (France). Eligible patients were 18 years old, with confirmed HIV status. Exclusion criteria were pregnancy, history of allergy, thyroid dysfunction, recent acute kidney injury, and treatment by metformin, steroids, trimethoprim, or cimetidine. The protocol was submitted and approved by Saint-Etienne's hospital institutional review board. The study was conducted in full compliance with the amended declaration of Helsinki following approval from the local ethical committee.

\section{GFR measurement}

GFR measurements were based on plasma clearance of iohexol (Omnipaque 300 GE Healthcare). After administration of $10 \mathrm{~mL}$ of iohexol intravenously, two blood samples were collected at approximately 120 and 240 minutes with exact time recorded. Iohexol plasma concentration was determined by High Performance Liquid Chromatography and Mass Spectrometry [26]. GFR was calculated using previously described protocol [27]. Measured GFR was reported to body surface area (BSA) as estimated by the Dubois \& Dubois formula [28].

\section{Laboratory Methods}

Blood and urine samples were stored at $-80^{\circ} \mathrm{C}$. Scr was measured by IDMS-traceable enzymatic method (Orthoclinical diagnostics, United Kingdom, CV $5.6 \%$ at $0.71 \mathrm{mg} / \mathrm{dL}$, and $2.1 \%$ at $5.82 \mathrm{mg} / \mathrm{dL}$ ). Scyst was measured by IFCC-traceable (International Federation of Clinical Chemistry) nephelometric method (Siemens, Germany) on a Siemens BN Prospec analyzer (CV of $2.9 \%$ at $1.03 \mathrm{mg} / \mathrm{L}$ and $2.1 \%$ at $1.93 \mathrm{mg} / \mathrm{L}$ ) [17]. HIV-viral load was determined by Abbott m2000 real-time HIV-1 assay (Abbott diagnostics, France). CD4+ lymphocytes count -was measured by flow cytometry at the time of GFR measurement. Urine microalbumin was determined by immunonephelometry on a Siemens BN ProSpec. Sensitivity of the assay is $0.16 \mathrm{mg} / \mathrm{dL}$ with inter-assay CV's of $3.0 \%$. 


\section{Data collection}

Clinical variables collected at the time of GFR measurement were: sex, age, height, weight, time since HIVinfection diagnosis, history of injecting drug use, smoking status, history of hypertension, dyslipidemia and/or diabetes mellitus (DM), HAART regimen, hepatitis B virus and hepatitis C virus status, liver cirrhosis. In the study, DM was defined as a diagnosis of DM prior to the study or use of oral anti-diabetic agents or insulin at the time of enrollment. Hypertension was defined as systolic blood pressure $>140 \mathrm{mniHg}$, diastolic blood pressure $>90 \mathrm{mniHg}$ or the use of antihypertensive agents. Dyslipidemia was defined as triglycerides greater than $2 \mathrm{~g} / \mathrm{L}$ or use of fibrates at the time of enrollment, or LDL-cholesterol greater than $1.60 \mathrm{~g} / \mathrm{L}$ or use of statins at the time of enrollment.

Biological variables collected at the time of GFR measurement were: HIV viral load, CD4 positive lymphocyte count, C-reactive protein (CRP), urinary albumin/creatinine ratio (ACR), serum Scyst and Scr.

Analysis of the performance of GFR estimating equations and statistics GFR was estimated with the MDRD study equation [29], the CKD-EPI equation [10], the CKD-EPI Cys equation and the CKD-EPI combined equation [18] (Table 1). We considered the African-American (AA) coefficient factor as not applicable to black subjects from Africa, Europe or Antilles [30].

Simple linear regression was used to calculate the Pearson's correlation coefficients between measured GFR (inGFR) and estimated GFR (eGFR) by the four equations.

The predictive performance of the four GFR estimates was assessed with the following parameters:

(1) Absolute bias, defined as the mean difference between eGFR and mGFR, a negative value meaning that eGFR under-estimates true GFR.

(2) Relative bias, calculated as absolute bias/mGFR x 100

(3) Precision, evaluated by the standard deviation of the mean difference between eGFR and mGFR (absolute and relative)

(4) Accuracy, defined as the proportion of eGFR values within $+/-30 \%$ of the mGFR.

(5) Agreement, evaluated by the Bland and Altman method [31].

Table 1. GFR estimates (SCr serum creatinine, Scyst serum cystatine C).

\begin{tabular}{|c|c|c|}
\hline Basis of equation and sex & Scr and Scyst values & Equation for estimating GFR \\
\hline MDRD & & $175 \times$ Scr $^{-1.154} \times$ age $^{-0.203} \times[0.742$ if female $]$ \\
\hline \multicolumn{3}{|r|}{ 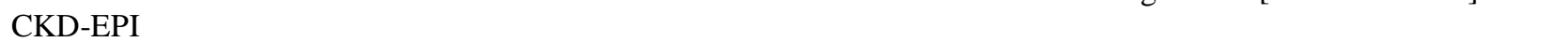 } \\
\hline \multirow[t]{2}{*}{ Female } & $\mathrm{SCr} \leq 0.7 \mathrm{mg} / \mathrm{dL}$ & $144 \times(\mathrm{Scr} / 0.7)^{0.329} \times 0.993^{\text {age }}$ \\
\hline & $\mathrm{SCr}>0.7 \mathrm{mg} / \mathrm{dL}$ & $144 \times(\mathrm{Scr} / 0.7)^{-1.209} \times 0.993^{\text {age }}$ \\
\hline \multirow[t]{2}{*}{ Male } & $\mathrm{SCr} \leq 0.9 \mathrm{mg} / \mathrm{dL}$ & $141 \times(\mathrm{Scr} / 0.9)^{-0.411} \times 0.993^{\text {age }}$ \\
\hline & $\mathrm{SCr}>0.9 \mathrm{mg} / \mathrm{dL}$ & $141 \times(\mathrm{Scr} / 0.9)^{-1.209} \times 0.993^{\text {age }}$ \\
\hline \multirow[t]{2}{*}{ CKD-EPI Scyst } & Scyst $\leq 0.8 \mathrm{mg} / \mathrm{L}$ & $133 \times(\text { Scyst } / 0,8)^{-0.499} \times 0.996^{\text {age }}[\times 0.932$ if female $]$ \\
\hline & SCyst $>0.8 \mathrm{mg} / \mathrm{L}$ & $133 \times(\text { Scys } / 0,8)^{-1.328} \times 0.996^{\text {age }}[\mathrm{x} 0.932$ if female $]$ \\
\hline \multicolumn{3}{|l|}{ CKD-EPI combined } \\
\hline \multirow[t]{4}{*}{ Female } & $\mathrm{SCr} \leq 0.7 \mathrm{mg} / \mathrm{dL}$ and Scyst $\leq 0.8 \mathrm{mg} / \mathrm{dL}$ & $130 \times(\mathrm{Scr} / 0.7)^{-0.248} \times(\text { Scyst } / 0.8)^{-0.375} \times 0.995^{\text {age }}$ \\
\hline & $\mathrm{SCr} \leq 0.7 \mathrm{mg} / \mathrm{dL}$ and Scyst $>0.8 \mathrm{mg} / \mathrm{dL}$ & $130 \times(\mathrm{Scr} / 0.7)^{-0.248} \times(\mathrm{Scyst} / 0.8)^{-0.711} \times 0.995^{\text {age }}$ \\
\hline & $\mathrm{SCr}>0.7 \mathrm{mg} / \mathrm{dL}$ and $\mathrm{Scyst} \leq 0.8 \mathrm{mg} / \mathrm{dL}$ & $130 \times(\mathrm{Scr} / 0.7)^{-0.601} \times(\mathrm{Scyst} / 0.8)^{-0.375} \times 0.995^{\text {age }}$ \\
\hline & $\mathrm{SCr}>0.7 \mathrm{mg} / \mathrm{dL}$ and Scyst $>0.8 \mathrm{mg} / \mathrm{dL}$ & $130 \times(\mathrm{Scr} / 0.7)^{-0.601} \times(\mathrm{Scyst} / 0.8)^{-0.711} \times 0.995^{\text {age }}$ \\
\hline \multirow[t]{4}{*}{ Male } & $\mathrm{SCr} \leq 0.9 \mathrm{mg} / \mathrm{dL}$ and Scyst $\leq 0.8 \mathrm{mg} / \mathrm{dL}$ & $135 \times(\mathrm{Scr} / 0.9)^{-0.207} \times(\text { Scyst } / 0.8)^{-0.375} \times 0.995^{\text {age }}$ \\
\hline & $\mathrm{SCr} \leq 0.9 \mathrm{mg} / \mathrm{dL}$ and Scyst $>0.8 \mathrm{mg} / \mathrm{dL}$ & $135 \times(\mathrm{Scr} / 0.9)^{-0.207} \times(\text { Scyst } / 0.8)^{-0.711} \times 0.995^{\text {age }}$ \\
\hline & $\mathrm{SCr}>0.9 \mathrm{mg} / \mathrm{dL}$ and Scyst $\leq 0.8 \mathrm{mg} / \mathrm{dL}$ & $135 \times(\mathrm{Scr} / 0.9)^{-0.601} \times(\mathrm{Scyst} / 0.8)^{-0.375} \times 0.995^{\text {age }}$ \\
\hline & $\mathrm{SCr}>0.9 \mathrm{mg} / \mathrm{dL}$ and Scyst $>0.8 \mathrm{mg} / \mathrm{dL}$ & $135 \times(\mathrm{Scr} / 0.7)^{-0.601} \times(\mathrm{Scyst} / 0.8)^{-0.711} \times 0.995^{\text {age }}$ \\
\hline
\end{tabular}

The relative performance of the GFR estimating equations was evaluated by comparing: (i) the precision using F-test and (ii) the accuracy using McNemar paired test or McNemar's exact test in case of sparse data (some cells $<5)$. The relative performance of the GFR estimating equations was evaluated on the whole population and in subgroups defined by mGFR, by age, BMI, smoking status, HIV-viral load, CD4 positive cells count, and 
HAART regimen containing or not tenofovir. Additionally, we evaluated the performance of the equations for classification of patients having an iohexol clearance above or below $60 \mathrm{ml} / \mathrm{min} / 1.73 \mathrm{~m}^{2}$ using the net reclassification index statistic.

Statistical analysis were performed with SPSS version 17.0 (SPSS, Chicago, IL) and R 2.15.1 (R development Core Team, Vienna, Austria), and GraphPad Prism 6 (GraphPad Software, Lajolla, CA).

Table 2. Patients characteristics Mean (SD) for continuous variables, $n(\%)$ for categorical variables.

Main characteristics of the population

\begin{tabular}{|c|c|}
\hline Age (year) & $49 \pm 10[22-84]$ \\
\hline Female & $37(18 \%)$ \\
\hline Time since HIV infection diagnosis (years) & $11 \pm 7$ \\
\hline Weight (kg) & $71 \pm 13[42-108]$ \\
\hline Height $(\mathrm{cm})$ & $172 \pm 8[155-195]$ \\
\hline African origin & $15(7)$ \\
\hline Body mass index $\left(\mathrm{kg} / \mathrm{m}^{2}\right)$ & $24 \pm 4[17-37]$ \\
\hline$<18$ & $11(5)$ \\
\hline$<25$ & $132(65)$ \\
\hline $25<\mathrm{BMI}<30$ & $50(25)$ \\
\hline $30>\mathrm{BMI}$ & $21(10)$ \\
\hline Diabetes & $13(6)$ \\
\hline Hypertension & $36(18)$ \\
\hline Smoker & $77(38)$ \\
\hline Drug abuser & $11(5)$ \\
\hline HAART & $189(93)$ \\
\hline Tenofovir usage & $111(55)$ \\
\hline \multicolumn{2}{|l|}{ HIV Viral Load } \\
\hline Undetected & $169(83)$ \\
\hline$<1000$ copies $/ \mathrm{mL}$ & $15(7)$ \\
\hline$>1000$ copies $/ \mathrm{mL}$ & $18(9)$ \\
\hline CD4 (cells $/ \mu \mathrm{L})$ & $593 \pm 262$ \\
\hline Hepatitis B & $10(5)$ \\
\hline Hepatitis C & $19(9)$ \\
\hline \multicolumn{2}{|l|}{$\operatorname{ACR}(m g / g)(n=202)$} \\
\hline$<30$ & $163(81)$ \\
\hline $30-300$ & $34(17)$ \\
\hline $300-1000$ & $3(1)$ \\
\hline$>1000$ & $2(1)$ \\
\hline Creatinine $(\mathrm{mg} / \mathrm{dL})$ & $0.87 \pm 0.19$ \\
\hline Cystatin C (mg/L) & $0.9 \pm 0.26$ \\
\hline lohexol GFR (mL/min/1.73m²) & $95 \pm 24$ [18-189] \\
\hline \multicolumn{2}{|l|}{ Chronic Kidney Disease (CKD) stage } \\
\hline 1. $\mathrm{GFR} \geq 90 \mathrm{~mL} / \mathrm{min} / 1.73 \mathrm{~m}^{2}$ & $118(58)$ \\
\hline 2. GFR $60-89 \mathrm{~mL} / \mathrm{min} / 1.73 \mathrm{~m}^{2}$ & $67(33)$ \\
\hline 3. GFR $30-59 \mathrm{~mL} / \mathrm{min} / 1.73 \mathrm{~m}^{2}$ & $16(8)$ \\
\hline 4. GFR $15-29 \mathrm{~mL} / \mathrm{min} / 1.73 \mathrm{~m}^{2}$ & $2(1)$ \\
\hline Hyperfiltrating status $\left(\mathrm{GFR}>120 \mathrm{~mL} / \mathrm{min} / 1.73 \mathrm{~m}^{2}\right)$ & $25(12)$ \\
\hline
\end{tabular}

Values expressed as mean \pm SD [range] or number (percent). ACR, urinary Albumine/Creatinine Ratio; GFR, Glomerular Filtration Rate; HAART, Highly active anti-retroviral therapies.

\section{Results}

Two hundred and five HIV-infected patients were enrolled between February 2011 and June 2012. Two of them were excluded from the analysis because one was a kidney transplant recipient and because the iohexol protocol was corrupted in the second one. Characteristics are summarized in Table 2. Mean age was $49 \pm 10$ years, $18 \%$ of patients were female. Mean body mass index was $24 \pm 4 \mathrm{~kg} / \mathrm{m}$ and $93 \%$ of the patients were Caucasian. Most patients were receiving HAART and had undetected HIV viral load at the time of GFR measurement (93\% and 
$83 \%$, respectively). HAART regimen contained tenofovir in $55 \%$ of the patients. History of diabetes mellitus and hypertension was present in 6 and $18 \%$ of the patients, respectively. Evidence for proteinuria (defined as ACR $>30 \mathrm{mg} / \mathrm{g}$ ) was found in 39 patients $(19 \%)$. Mean measured GFR was $95 \pm 24 \mathrm{~mL} / \mathrm{min} / 1.73 \mathrm{~m}^{2}$. Fifty eight percent $(\mathrm{n}=118)$ of the patients had $\mathrm{mGFR}$ greater than $90 \mathrm{~mL} / \mathrm{min} / 1.73 \mathrm{~m}^{2}$ and only $9 \%(\mathrm{n}=18)$ had niGFR less than $60 \mathrm{~mL} / \mathrm{min} / 1.73 \mathrm{~m}^{2}$.

Considering the whole study population (Table 3 and Fig. 1), the CKD-EPI equation provided the best accuracy of prediction (82\%), the MDRD study equation the worst $(75 \%)$. The combined equation exhibited comparable performance (Accuracy of $81 \%$ ) as compared to the CKD-EPI equation. Importantly, both the CKD-EPI and CKD-EPI combined equations demonstrated a significantly better accuracy than the MDRD study equation ( $\mathrm{p}=$ $0.002, p=0.016$ respectively Mac Nemar Test). By comparison, the equation based solely on Scyst did not significantly improve the accuracy of prediction $(80 \%$ vs $75 \%$ for the CKD-EPI Scyst equation and the MDRD study equation, respectively, $\mathrm{p}=0.12$, Mac Nemar Test).

Table 3. Predictive performances of the MDRD study, CKD-EPI, CKD-EPI-Scyst, and CKD-EPI-combined equations in HIV patients $(n=203)$.

\begin{tabular}{lccccc}
\hline GFR estimates & $\mathrm{R}$ & \multicolumn{2}{c}{ Bias } & \multicolumn{2}{c}{$\begin{array}{c}\text { Absolute Precision } \mathrm{mL} / \mathrm{min} / 1.73 \mathrm{~m}^{2} \text { (relative } \\
\text { in \%) }\end{array}$} \\
\cline { 2 - 5 } & & $\begin{array}{c}\text { Absolute } \\
\left(\mathrm{mL} / \mathrm{min} / 1.73 \mathrm{~m}^{2}\right)\end{array}$ & $\begin{array}{c}\text { Relative } \\
(\%)\end{array}$ & $25(33 \%)$ & 75 \\
MDRD & 0.41 & -1.1 & +4.2 & $22(31 \%)$ & $82^{*}$ \\
CKD-EPI & 0.51 & +2.6 & +8.3 & $22(26 \%)$ & 80 \\
CKD-EPI Scyst & 0.54 & +1.2 & +5 & $20(26 \%)$ & $81^{*}$ \\
CKD-EPI & 0.58 & +2.5 & +6.9 & & \\
combined & & & & & \\
\hline
\end{tabular}

${ }^{*} \mathrm{p}<0.05$ versus MDRD study equation, R: correlation coefficient.

Fig. 1. Bland and Altman plots of the MDRD study, CKD-EPI, CKD-EPI Scyst, CKD-EPI combined $(n=203)$.

MDRD

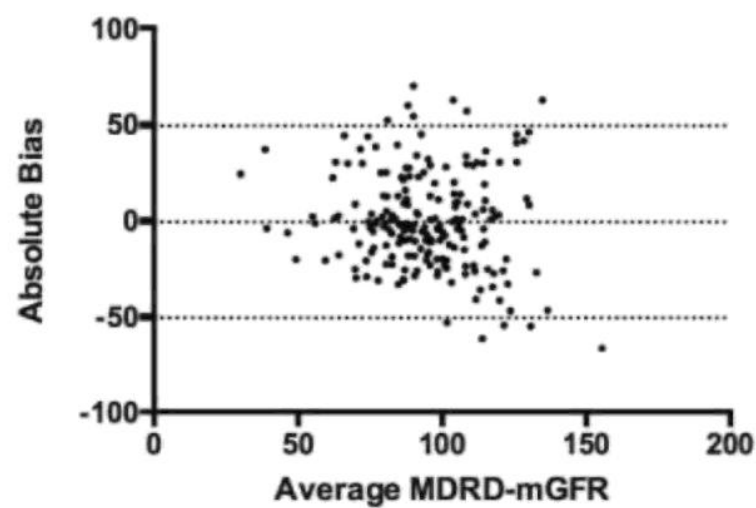

CKD-EPI

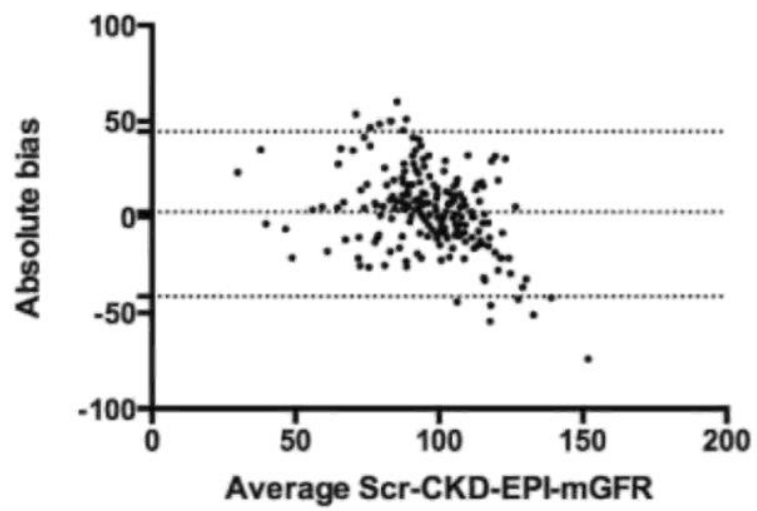



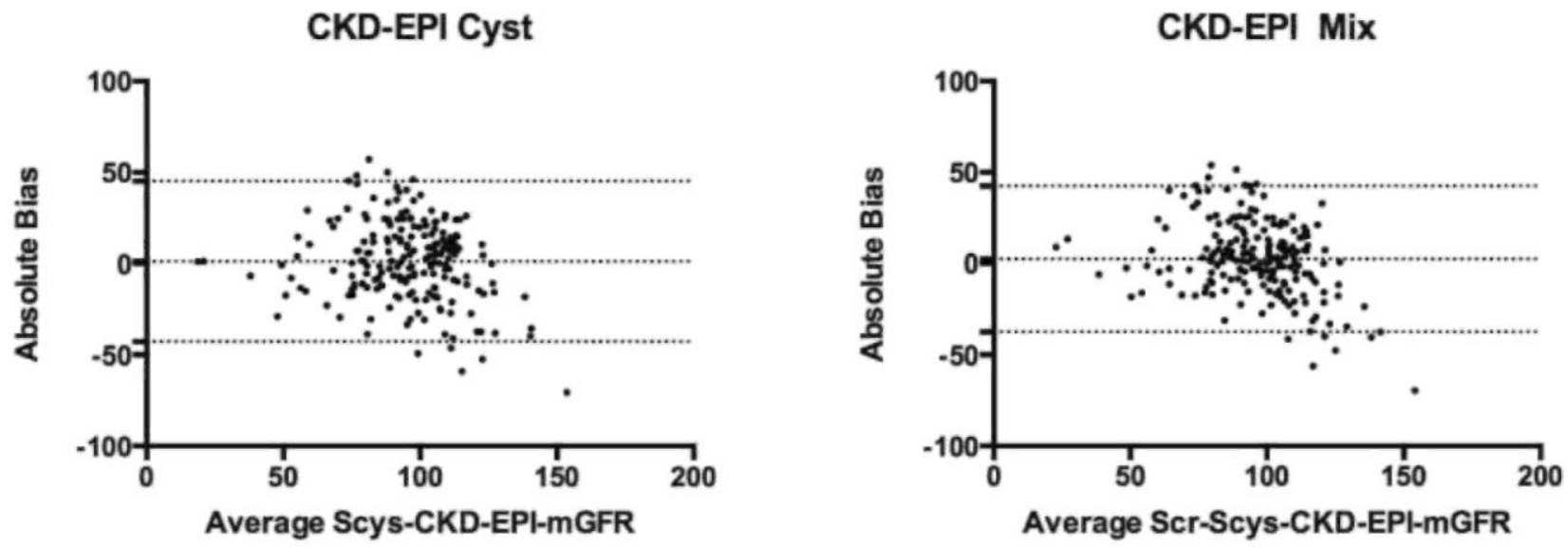

Table 4. Predictive performances of the MDRD study, CKD-EPI, CKD-EPI Scyst, and CKD-EPI combined equations in HIV patients according to different GFR levels.

\begin{tabular}{|c|c|c|c|c|}
\hline \multirow[t]{2}{*}{ GFR estimates } & \multicolumn{2}{|c|}{ Bias } & \multirow{2}{*}{$\begin{array}{c}\text { Absolute Precision } \\
\mathrm{mL} / \mathrm{min} / 1.73 \mathrm{~m}^{2} \\
\text { (relative in } \% \text { ) }\end{array}$} & \multirow{2}{*}{$\begin{array}{c}\text { Accuracy } \\
30 \%\end{array}$} \\
\hline & $\begin{array}{c}\text { Absolute } \\
\left(\mathrm{mL} / \mathrm{min} / 1.73 \mathrm{~m}^{2}\right)\end{array}$ & Relative (\%) & & \\
\hline \multicolumn{5}{|c|}{$m \mathrm{mGFR}<60 \mathrm{~mL} / \mathrm{min} / 1.73 \mathrm{~m}^{2}(n=18)$} \\
\hline MDRD & +27 & +61 & $25(58 \%)$ & 22 \\
\hline CKD-EPI & +29 & +66 & $24(55 \%)$ & 22 \\
\hline CKD-EPI Scyst & +18 & +34 & $22(41 \%)$ & 44 \\
\hline CKD-EPI combined & +23 & +47 & $21(40 \%)$ & 22 \\
\hline \multicolumn{5}{|c|}{$m G F R>60 \mathrm{~mL} / \mathrm{min} / 1.73 \mathrm{~m}^{2}(n=185)$} \\
\hline MDRD & -4 & -1 & $23(24 \%)$ & 80 \\
\hline CKD-EPI & 0 & +3 & $20(20 \%)$ & $88^{*}$ \\
\hline CKD-EPI Scyst & 0 & +2 & $21(22 \%)$ & 83 \\
\hline CKD-EPI combined & +1 & +3 & $20(20 \%)$ & $87 *$ \\
\hline \multicolumn{5}{|c|}{ mGFR: $60-90 \mathrm{~mL} / \mathrm{min} / 1.73 \mathrm{~m}^{2}(n=67)$} \\
\hline MDRD & +7 & +10 & $20(26 \%)$ & 75 \\
\hline CKD-EPI & +12 & +16 & $16(22 \%)$ & 76 \\
\hline CKD-EPI Scyst & +11 & +14 & $19(26 \%)$ & 67 \\
\hline CKD-EPI combined & +11 & +15 & $17(23 \%)$ & 73 \\
\hline \multicolumn{5}{|c|}{$m G F R: 90-120 \mathrm{~mL} / \mathrm{min} / 1.73 \mathrm{~m}^{2}(n=93)$} \\
\hline MDRD & -4 & -3 & $19(19 \%)$ & 87 \\
\hline CKD-EPI & -1 & 0 & $13(13 \%)$ & $99^{*}$ \\
\hline CKD-EPI Scyst & -1 & 0 & $15(15 \%)$ & $98^{*}$ \\
\hline CKD-EPI combined & 0 & +1 & $13(12 \%)$ & $98^{*}$ \\
\hline \multicolumn{5}{|c|}{$m G F R>90 \mathrm{~mL} / \mathrm{min} / 1.73 \mathrm{~m}^{2}(\eta=118)$} \\
\hline MDRD & -10 & -8 & $23(19 \%)$ & 83 \\
\hline CKD-EPI & -7 & -5 & $18(15 \%)$ & $95^{*}$ \\
\hline CKD-EPI Scyst & -7 & -5 & $20(16 \%)$ & $92 *$ \\
\hline CKD-EPI combined & -6 & -4 & $18(14 \%)$ & $95^{*}$ \\
\hline \multicolumn{5}{|c|}{$m G F R>120 \mathrm{~mL} / \mathrm{min} / 1.73 \mathrm{~m}^{2}(n=25)$} \\
\hline MDRD & -33 & -24 & $20(13 \%)$ & 68 \\
\hline CKD-EPI & -29 & -20 & $18(11 \%)$ & 80 \\
\hline CKD-EPI Scyst & -29 & -21 & $19(12 \%)$ & 72 \\
\hline CKD-EPI combined & -28 & -20 & $17(10 \%)$ & 84 \\
\hline
\end{tabular}

*p $<0.05$ versus MDRD study equation (Mc Nemar Test). 
Performances of the equation (bias, precision and accuracy) strongly varied according to the GFR levels (Table 4). While these performances were clearly insufficient in patients with $\mathrm{mGFR}$ under $60 \mathrm{~mL} / \mathrm{min} / 1.73 \mathrm{~m}{ }^{2}$, they were globally better above this cut-off. This was especially true for patients with mGFR between 90 and 120 $\mathrm{mL} / \mathrm{min} / 1.73 \mathrm{~m}^{2}$ (accuracy between 87 and 99\%). In this GFR range, the accuracy of the MDRD equation remained significantly inferior as compared to the 3 other equations (Table 4). None Scyst-based equations permitted to significantly improve the reclassification of patients around the threshold of $60 \mathrm{~mL} / \mathrm{min} / 1.73 \mathrm{~m}^{2}$ (Table 5).

Figure 2 shows the accuracy of the CKD-EPI equation and the 2 equations based on Scyst in different clinical subgroups. No advantage for the Scyst-based prediction was apparent.

\section{Discussion}

Estimating GFR in HIV patients is now recommended [5] as these patients seem at higher risk for CKD [1,2,4].

In our cohort of European patients, we studied the performance of the most recent Scr- and Scyst-based equations $[10,18,29]$. Considering the whole population, we demonstrate that the CKD-EPI equation has a better accuracy than the MDRD study equation.

Regarding the new Scyst-based equations, we show that none of them provide a more accurate estimation than the CKD-EPI equation. We thus confirm, for the first time in European patients, that the CKD-EPI equation should be the equation of first choice in the HIV-infected population. [10,25]. This result is not unexpected as the vast majority of our patients had normal or high mGFR $[10,13,18]$. As compared to data recently published in the general population, the performance of both the CKD-EPI Scyst and the CKD-EPI combined equation is somewhat disappointing. However our findings are consistent with other data obtained from another HIV cohort [25]. Several hypotheses can be drawn to explain the lack of advantage for Scyst in those patients. Many factors have indeed been proposed to influence Scyst levels independently of any GFR change, as inflammation and tobacco for instance [14,32-34]. More specifically, it has been suggested that HIV viral load could also influence Scyst levels [35,36]. In our cohort, accuracies are similar for the three equations in the group of smokers in comparison with the non-smokers. However, we observe a trend for a better accuracy of the CKD-EPI as compared to the CKD-EPI Scyst in patients with detectable HIV-viral load.

Performances of the four equations were particularly poor in patients with GFR under $60 \mathrm{~mL} / \mathrm{min} / 1.73 \mathrm{~m}^{2}$. This observation is at odds with what is usually reported in the general population where the predictive performance of equations usually improves with decreasing GFR [29]. Here again, the same observation was previously made in HIV-infected patients [25]. Our observation was consistent with this previous study and further suggests the difficulty in accurately evaluating renal function in HIV-infected patients, a population with specific characteristics that make it different from the general population in many regards. These patients with lower mGFR are probably the patients who are frailer, notably in term of muscular mass (they were, in our cohort, older than patients with niGFR $>60 \mathrm{~mL} / \mathrm{min} / 1.73 \mathrm{~m}^{2}$, data not shown).

In the context of CKD screening, it is particularly important to assess the performance of the equation "around" $60 \mathrm{~mL} / \mathrm{min} / 1.73 \mathrm{~m}^{2}$ which is considered as the "threshold" value for CKD diagnosis by several, but not all, authors $[37,38]$. In this view, the rather good results observed when considering the whole population must here again be tempered. In the subgroup of mGFR between 60 and $90 \mathrm{~mL} / \mathrm{min} / 1.73 \mathrm{~m}^{2}$, a subgroup which is both clinically and quantitatively important, all the equations - even the CKD-EPI equation - exhibit suboptimal performance with accuracy below $80 \%$.

To the best of our knowledge, only the study recently published by Inker and colleagues has used calibrated Scyst and Scr. In this study, the authors studied the performances of the MDRD, CKD-EPI, CKD-EPI Scyst and CKD-EPI combined equations in $200 \mathrm{HIV}$ patients from USA [25]. Interestingly, they measured, like us, GFR with iohexol plasma clearance. While cohorts' characteristics are quite different between Inker's study and ours (52\% of African-American in the Inker's study; mean BMI $27 \mathrm{~kg} / \mathrm{m}$ in Inker's $v s 24 \mathrm{~kg} / \mathrm{m}$; more Intravenous drug user in the American Cohort, higher proportion of patients with undetected viral load in ours), our findings are mostly in agreement and provide a confirmation in a European cohort of the superiority of the CKD-EPI equation in HIV-infected patients. 
Table 5. Net reclassification improvements (NRI) of CKD-EPI Scyst and combined equations compared to CKDEPI equation at $60 \mathrm{~mL} / \mathrm{min} / 1.73 \mathrm{~m}^{2}$.

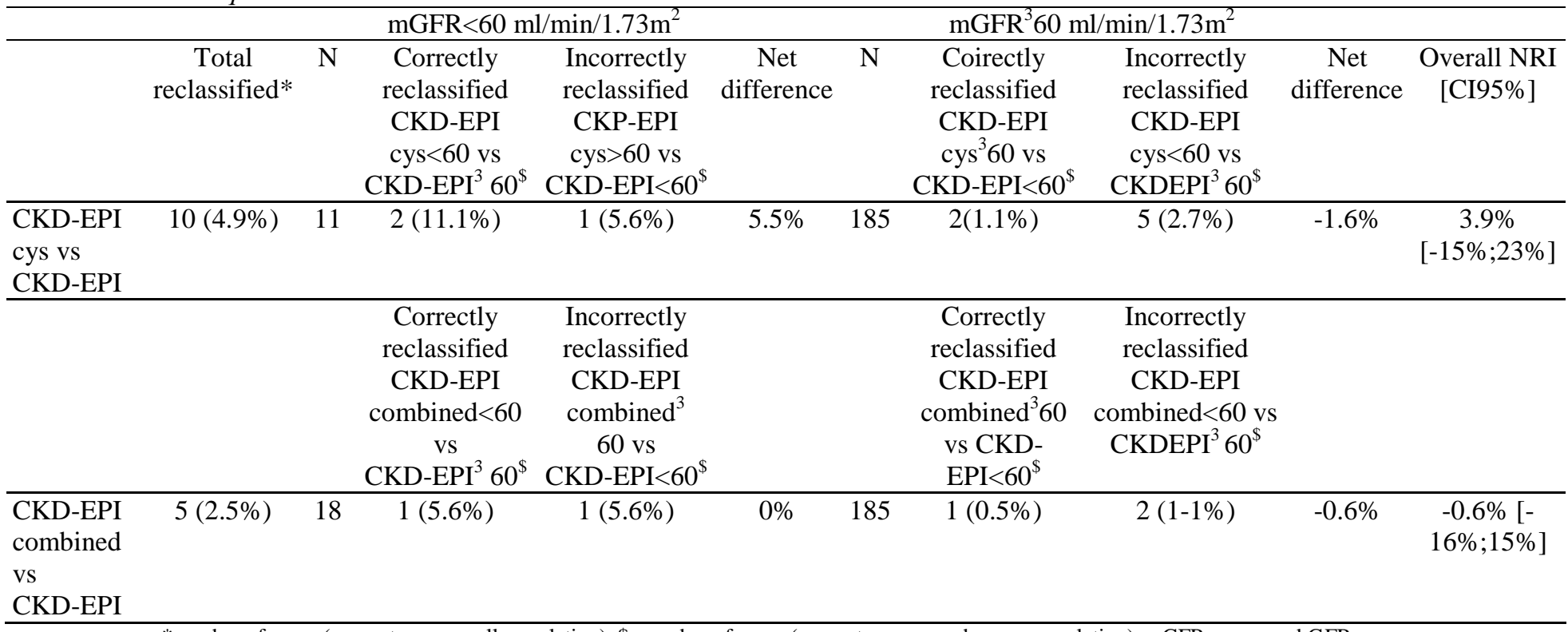

*number of cases (percentage over all population). \$: number of cases (percentage over subgroup population). mGFR: measured GFR.

Some limitations of our study must be considered. The study population includes only few patients with mGFR under $60 \mathrm{~mL} / \mathrm{min} / 1.73 \mathrm{~m}^{2}$. Results observed in the subgroup of low GFR must thus be considered with caution. Our patients are almost exclusively Caucasians. Only 15 patients were identifed as blacks (of note, no ethnic coefficient was specifically used for those patients). For patients with marked renal impairment (less than $10 \%$ of our study population), an additional and later measurement of iohexol is usually recommended but was not performed in our study. Finally, since very few patients were not receiving HAART and had a detectable HIV viral load, our results cannot be extrapolated to all HIV-infected patients.

In conclusion, we demonstrate that the CKD-EPI equation outperforms the MDRD study equation in European HIV-infected patients. Recent equations including standardized Scyst values do not provide any advantage in this population. The current guidelines regarding the preferential utilization of the CKD-EPI equation in the general population are thus also valid for estimating renal function of HIV-infected patients in the US as well as in Europe. Clinicians must however keep in mind that the estimation of renal function provided by the CKD-EPI equation remains probably suboptimal for HIV-positive patients with decreased GFR.

Fig. 2. Accuracies in different sub-groups of patients The number of patients for each subgroups was 119 and 84 for age $\leq 50$ years and $>50$ respectively, 132 and 71 for $B M I \leq 25$ and $>25 \mathrm{~kg} / \mathrm{m}^{2}$ respectively, 77 in the groups of smokers vs 126 no smokers, 33 patients with a HIV viral load detectable, 37 with a CD4 positive count under 350/mm3, 111 were receiving tenofovir.
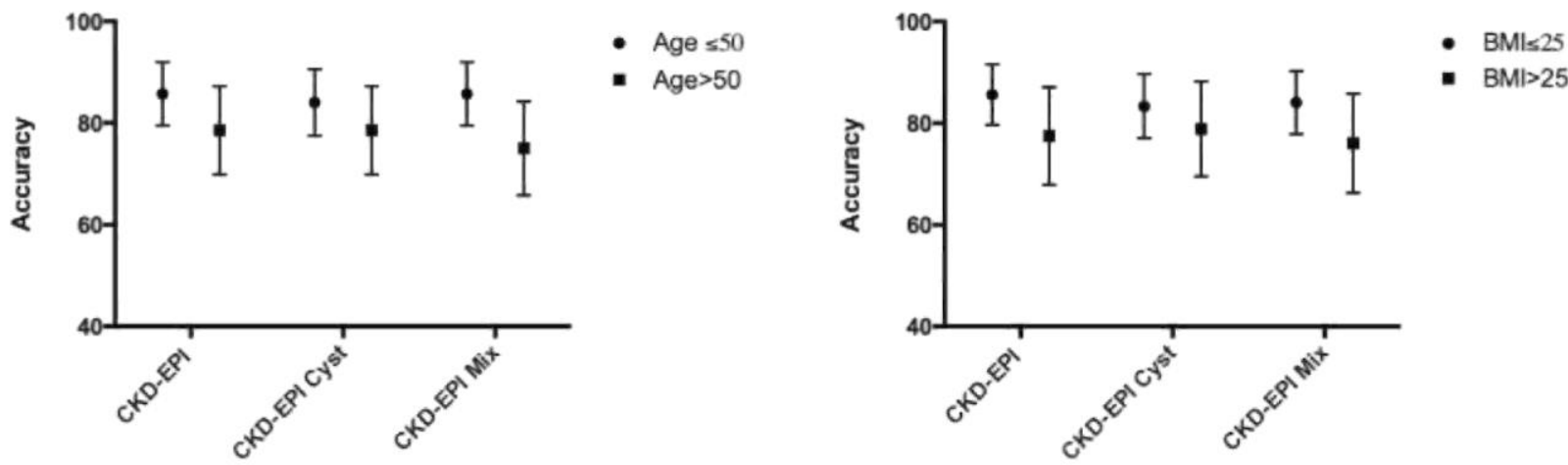

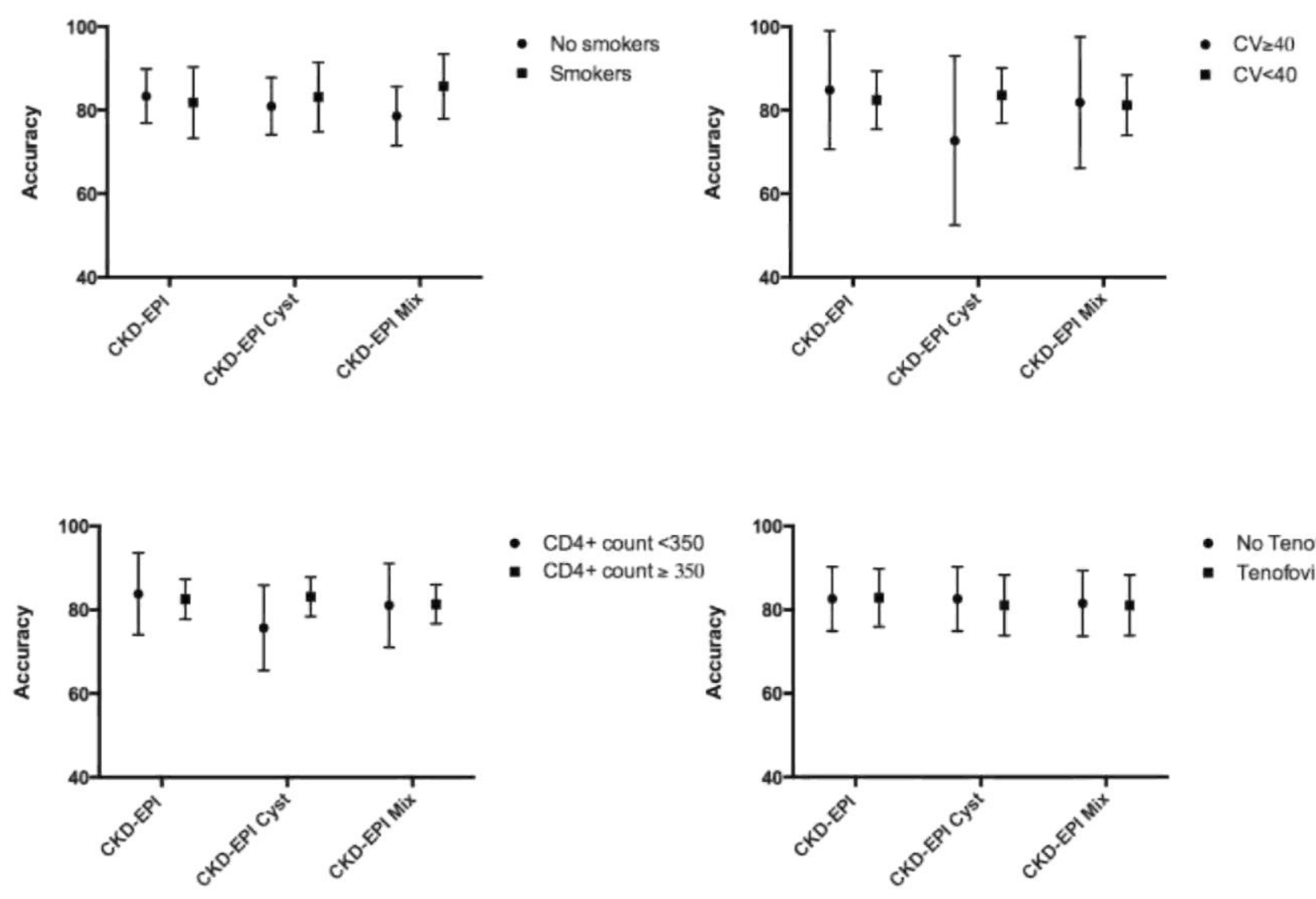

- CD4+ count $<350$

- $\mathrm{CD} 4+$ count $\geq 350$

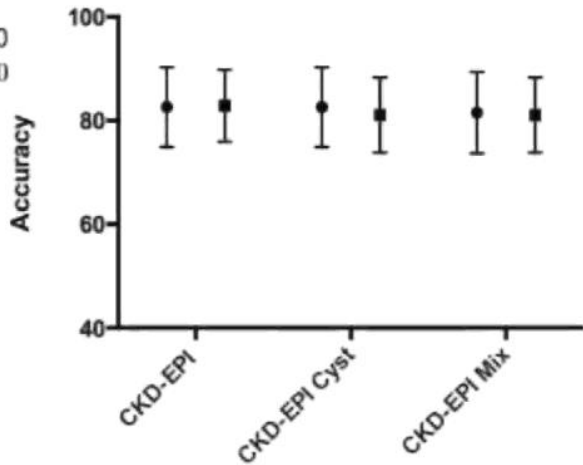

- No Tenofovir

- Tenofovir

\section{Acknowledgements}

\section{Conflicts of interest}

The authors declare they have no conflict of interest.

Financial support: Universitary Hospital of Saint-Etienne, France

\section{References}

1. Estrella MM, Fine DM, Atta MG. Recent developments in HIV-related kidney disease. HIV Ther 2010; 4:589-603.

2. Estrella MM, Parekh RS, Abraham A, Astor BC, Szczech LA, Anastos K, et al. The impact of kidney function at highly active antiretroviral therapy initiation on mortality in HIV-infected women. J Acquir Immune Defic Syndr 2010; 55:217-220.

3. Szczech LA, Hoover DR, Feldman JG, Cohen MH, Gange SJ, Goozé L, et al. Association between renal disease and outcomes among HIV-infected women receiving or not receiving antiretroviral therapy. Clin Infect Dis 2004; 39:1199-1206.

4. Gagneux-Brunon A, Mariat C, Delanaye P. Cystatin C in HIV-infected Patients: Promising but Not yet Ready for Prime Time. Nephrol Dial Transplant 2012; 27:1305-1313.

5. Gupta SK, Eustace JA, Winston JA, Boydstun II, Ahuja TS, Rodriguez RA, et al. Guidelines for the management of chronic kidney disease in HIV-infected patients: recommendations of the HIV Medicine Association of the Infectious Diseases Society of America. Clin Infect Dis 2005; 40:1559-1585

6. Delanaye P, Cohen EP. Formula-based estimates of the GFR: equations variable and uncertain. Nephron Clin Pract 2008; 110:c48-c53; discussion c54

7. Froissart M, Rossert J, Jacquot C, Paillard M, Houillier P. Predictive performance of the modification of diet in renal disease and Cockcroft-Gault equations for estimating renal function, $J$ Am Soc Nephrol 2005; 16:763-773. 
8. Glassock RJ, Winearls C. An epidemic of chronic kidney disease: fact or fiction? Nephrol Dial Transplant 2008; 23:1117-1121.

9. Jain AK, McLeod I, Huo C, Cuerden MS, Akbari A, Tonelli M, et al. When laboratories report estimated glomerular filtration rates in addition to serum creatinines, nephrology consults increase. Kidney Int 2009; 76:318-323.

10. Levey AS, Stevens LA, Schmid CH, Zhang YL. Castro AF 3rd, Feldman HI, et al. A new equation to estimate glomerular filtration rate. Ann Intern Med 2009; 150:604-612.

11. Björk J, Jones I, Nyman U, Sjöström P. Validation of the Lund-Malmö, Chronic Kidney Disease Epidemiology (CKD-EPI) and Modification of Diet in Renal Disease (MDRD) equations to estimate glomerular filtration rate in a large Swedish clinical population. Scand J Urol Nephrol 2012; 46:212-222.

12. Eriksen BO, Mathisen UD, Melsom T, Ingebretsen OC, Jenssen TG, Njolstad I, et al. Cystatin C is not a better estimator of GFR than plasma creatinine in the general population. Kidney Int 2010; 78:1305-1311.

13. Murata K, Baumann NA, Saenger AK, Larson TS, Rule AD, Lieske JC. Relative performance of the MDRD and CKD-EPI equations for estimating glomerular filtration rate among patients with varied clinical presentations. Clin J Am Soc Nephrol 2011; 6:1963-1972.

14. Séronie-Vivien S, Delanaye P, Piéroni L, Mariat C, Froissart M, Cristol J-P. Cystatin C: current position and future prospects. Clin Chem Lab Med 2008; 46:1664-1686.

15. Koteff J, Borland J, Chen S, Song I, Peppercorn A, Koshiba T, et al. A phase 1 study to evaluate dolutegravir's effect on renal function via measurement of iohexol and para-aminohippurate clearance in healthy subjects. Br J Clin Pharmacol Published Online First: 20 August 2012. doi:10.1111/j.1365-2125.2012.04440.x.

16. German P, Liu HC, Szwarcberg J, Hepner M, Andrews J, Kearney BP, et al. Effect of cobicistat on glomerular filtration rate in subjects with normal and impaired renal function, J Acquir Immune Defic Syndr 2012; 61:32-40.

17. Grubb A, Blirup-Jensen S, Lindström V, Schmidt C, Althaus H, Zegers I. First certified reference material for cystatin C in human serum ERM-DA471/IFCC. Clin Chem Lab Med 2010; 48:1619-1621.

18. Inker LA, Schmid CH, Tighiouart H, Eckfeldt JH, Feldman HI, Greene T, et al. Estimating glomerular filtration rate from serum creatinine and cystatin C. N Engl J Med 2012; 367:20-29.

19. Barraclough K, Er L, Ng F, Harris M, Montaner J, Levin A. A comparison of the predictive performance of different methods of kidney function estimation in a well-characterized HIV-infected population. Nephron Clin Pract 2009; 111:c39-c48.

20. Beringer PM, Owens H, Nguyen A, Mordwinkin N, Louie S, Mak M, et al. Estimation of glomerular filtration rate by using serum cystatin C and serum creatinine concentrations in patients with human immunodeficiency virus. Pharmacotherapy 2010; 30:1004-1010.

21. Bonjoch A, Bayés B, Riba J, Puig J, Estany C, Perez-Alvarez N, et al. Validation of estimated renal function measurements compared with the isotopic glomerular filtration rate in an HIV-infected cohort. Antiviral Res 2010; 88:347-354.

22. van Deventer HE, PaikerJE, Katz IJ, George JA. Acomparison of cystatin C- and creatinine-based prediction equations for the estimation of glomerular filtration rate in black South Africans. Nephrology Dialysis Transplantation 2011; 26:1553-1558.

23. Vrouenraets SME, Fux CA, Wit FWNM, Garcia EF, Brinkman K, Hoek FJ, et al. A comparison of measured and estimated glomerular filtration rate in successfully treated HIV-patients with preserved renal function. Clin Nephrol 2012; 77:311-320.

24. Praditpornsilpa K, Avihingsanon A, Chaiwatanarat T, Chaiya-hong P, Wongsabut J, Ubolyam S, et al. Comparisons between validated estimated glomerular filtration rate equations and isotopic glomerular filtration rate in HIV patients. AIDS 2012; 26:1781-1788.

25. Inker LA, Wyatt C, Creamer R, Hellinger J, Hotta M, Leppo M, et al. Performance of creatinine and cystatin C GFR estimating equations in an HIV-positive population on antiretrovirals. J Acquir Immune Defic Syndr 2012; 61:302-309.

26. Cavalier E, Rozet E, Dubois N, Charlier C, Hubert P, Chapelle J-P, et al. Performance of iohexol determination in serum and urine by HPLC: validation, risk and uncertainty assessment. Clin Chim Acta 2008; 396:80-85.

27. Bröchner-Mortensen J, Haahr J, Christoffersen J. A simple method for accurate assessment of the glomerular filtration rate in children. Scand J Clin Lab Invest 1974; 33:140-143.

28. Du Bois D, Du Bois EF. A FORMULA TO ESTIMATE THE APPROXIMATE SURFACE AREA IF HEIGHT AND WEIGHT BE KNOWN. Arch Intern Med 1916; XVII:863-871.

29. Levey AS, Coresh J, Greene T, Stevens LA, Zhang YL, Hendrik-sen S, et al. Using standardized serum creatinine values in the modification of diet in renal disease study equation for estimating glomerular filtration rate. Ann Intern Med 2006; 145:247-254

30. Delanaye P, Mariat C, Maillard N, Krzesinski J-M, Cavalier E. Are the Creatinine-Based Equations Accurate to Estimate Glomerular Filtration Rate in African American Populations? Clinical Journal of the American Society of Nephrology 2011; 6:906-912. 
31. Bland JM, Altman DG. Statistical methods for assessing agreement between two methods of clinical measurement. Lancet 1986; $1: 307-310$

32. Knight EL, VerhaveJC, Spiegelman D, Hillege HL, de Zeeuw D, Curhan GC, et al. Factors influencing serum cystatin C levels other than renal function and the impact on renal function measurement. Kidney Int 2004; 65:1416-1421.

33. Rule AD, Bergstralh EJ, Slezak JM, Bergert J, Larson TS. Glomerular filtration rate estimated by cystatin C among different clinical presentations. Kidney Int 0000; 69:399-405.

34. Stevens LA, Schmid CH, Greene T, Li L, Beck GJ, Joffe MM, et al. Factors other than glomerular filtration rate affect serum cystatin C levels. Kidney Int 2009; 75:652-660.

35. Mauss S, Berger F, KuschakD, Henke J, Hegener P, Wolf E, et al. Cystatin C as a marker of renal function is affected by HIV replication leading to an underestimation of kidney function in HIV patients. Antivir Ther (Lond) 2008; 13:1091-1095.

36. Longenecker CT, Scherzer R, Bacchetti P, Lewis CE, Grunfeld C, Shlipak MG. HIV viremia and changes in kidney function. AIDS $2009 ; 23: 1089-1096$.

37. Delanaye P, Schaeffner E, Ebert N, Cavalier E, Mariat C, Krze-sinski J-M, et al. Normal reference values for glomerular filtration rate: what do we really know? Nephrol Dial Transplant 2012; 27:2664-2672.

38. Levey AS, de Jong PE, Coresh J, El Nahas M, Astor BC, Matsushita K, et al. The definition, classification, and prognosis of chronic kidney disease: a KDIGO Controversies Conference report. Kidney Int 2011 ; 80:17-28. 